\title{
Depth Perception with a Newly Developed Microscope Stereotest
}

\author{
Kayo Shinomiya' \\ Takashi Fujikado ${ }^{2}$ \\ Akiko Kitora' \\ Satoe Okamoto' \\ Akiko Iwata' \\ Yoko Ogushi' \\ Yoshinori Mitamura (1D) \\ 'Department of Ophthalmology, \\ Graduate School of Medicine, Tokushima \\ University, Tokushima, Japan; ${ }^{2}$ Graduate \\ School of Frontier Biosciences, Osaka \\ University, Suita, Osaka, Japan
}

Purpose: We aimed to compare the depth perception under a microscope between binocular and monocular conditions using a newly developed microscopic stereotest (M-stereotest) and examine the effect of anisometropia on depth perception under a microscope.

Subjects and Methods: Thirty young and healthy subjects were examined. A manipulator attached with a stainless wire was placed under the objective lens of a stereomicroscope. The wire was moved up manually, and the subjects were instructed to stop the knob movement once the wire reached the same height as the fixed two wires. The deviation from the height of the fixed wires was measured under a best optically corrected binocular, a best optically corrected monocular, or an anisometropic binocular $[ \pm 3$ diopters (D) in the dominant or nondominant eye] condition.

Results: The deviation was significantly smaller in the binocular condition than in the monocular dominant eye condition $(0.38 \pm 0.26 \mathrm{~mm}$ vs $1.89 \pm 1.15 \mathrm{~mm}, \mathrm{p}<0.001)$ and was also significantly smaller in the best optically corrected binocular than in the anisometropic binocular condition $[1.07 \pm 1.00 \mathrm{~mm}(-3.0 \mathrm{D}), \mathrm{p}=0.003 ; 0.85 \pm 0.67 \mathrm{~mm}(+3.0 \mathrm{D})$, $\mathrm{p}<0.001]$.

Conclusion: Depth perception under the microscope is more accurate under the binocular than in the monocular condition, indicating the potential role of stereopsis. Anisometropia deteriorates depth perception, suggesting that refractive error should be corrected during microscopic work, such as during ophthalmic surgery.

Keywords: anisometropia, dynamic stereopsis, stereopsis, three-rods test

\section{Introduction}

The microscope has been used routinely in surgery and in the ophthalmology field. Many surgeries are performed under a microscope, highlighting the importance of depth perception. Stereopsis detected by Randot Stereotest is worse with a microscope than without a microscope. ${ }^{1}$

Depth perception can be obtained by both disparity and monocular cues, including accommodation, perspective, overlay, texture, and motion parallax. ${ }^{2-4}$ Randot Stereotest measures depth perception only based on disparity owing to its lack of monocular cues. The three-rods test can measure depth perception at a far distance and is used to test the suitability of professional drivers in Japan. ${ }^{5}$ Helmholz originally described the three-rods test in $1866 .{ }^{6}$ Moving rods enable monocular cues, such as accommodation, and a disparity cue. Hirai et al created a prototype of the three-rods test under the microscope (M-three-rods test) and reported that depth perception was better under a binocular viewing condition than under a monocular viewing condition. ${ }^{7,8}$
Correspondence: Kayo Shinomiya Department of Ophthalmology, Graduate School of Medicine, Tokushima University, 3-18-15, Kuramoto-cho, Tokushima, 770-8503, Japan

$\mathrm{Tel}+8 \mathrm{I} 088-633-7 \mid 63$

Fax +8I 088-63I-4848

Email shinomi@tokushima-u.ac.jp 
Although bars are aligned vertically in the ordinal threerods test, in our newly developed microscopic stereotest (M-stereotest), bars are aligned horizontally because surgeons use apparatus (such as a cutter) for vitrectomy horizontally. However, with normal static stereopsis, some individuals cannot perceive images stereoscopically under a microscope. In this study, we examined the factors that affect depth perception under the microscope using the M-stereotest in individuals with normal static stereopsis.

\section{Subjects and Methods}

Thirty healthy subjects (18 males and 12 females; age range, 19-29 years; mean \pm standard deviation, $22.5 \pm$ 2.3 years) with no ocular disease, other than refractive error, and with normal static stereopsis (60 $\mathrm{s}$ or better by the Titmus stereo test and TNO stereo test) were examined and included. This study was approved by the Institutional Review Board of the Tokushima University Hospital (Approval number: 1624) and was conducted in adherence to the tenets of the Declaration of Helsinki. Signed informed consent was obtained from all study subjects.

A manipulator attached with a stainless wire $(0.55 \mathrm{~mm}$ in diameter and $50 \mathrm{~mm}$ in length) was placed under the objective lens of a stereomicroscope with a Galileo-type parallel optical system (OLYMPUS Inc., Tokyo, Japan; Figure 1). The magnification of the microscope was set to $5 \times(10 \times$ eyepieces and $0.5 \times$ objective lenses). At the beginning of the experiment, the subject determined the best focus by adjusting the pupillary distance and then by adjusting the diopter (D) by moving the objective lens to the fixed two bars with both eye open condition. The objective lens was fixed during the experiment. Microscope illumination uses a near vertical illumination; hence, the experiment was performed in a bright room. The wire attached to the manipulator (set at the right side of the microscope) was moved up, while a knob was turned to the right or left. The subjects were instructed to stop the knob once the wire reached the same height as the fixed two wires (set at the left side of the microscope). They moved the knob in only one direction, from the bottom to the top, without repeating it. There was no time limit for the right hand until the subjects judged that they were at the same height. The examiner read the value of deviation in $0.1-\mathrm{mm}$ increments using a micrometer.

The deviation by M-stereotest was measured under binocular or monocular viewing conditions. A $-3.0 \mathrm{D}$ or +3.0 $D$ lens was added to the best optically corrected lens to define the refractive status as either best optical correction in both eyes or anisometropia. The best optical correction was determined by refraction and visual acuity tests. The participants used a trial frame, and the spherical lens power was the sum of the best-corrected optical power and the corresponding + +-3.0 D.

Participants underwent the experiments while wearing their best optically corrected lenses under monocular
A

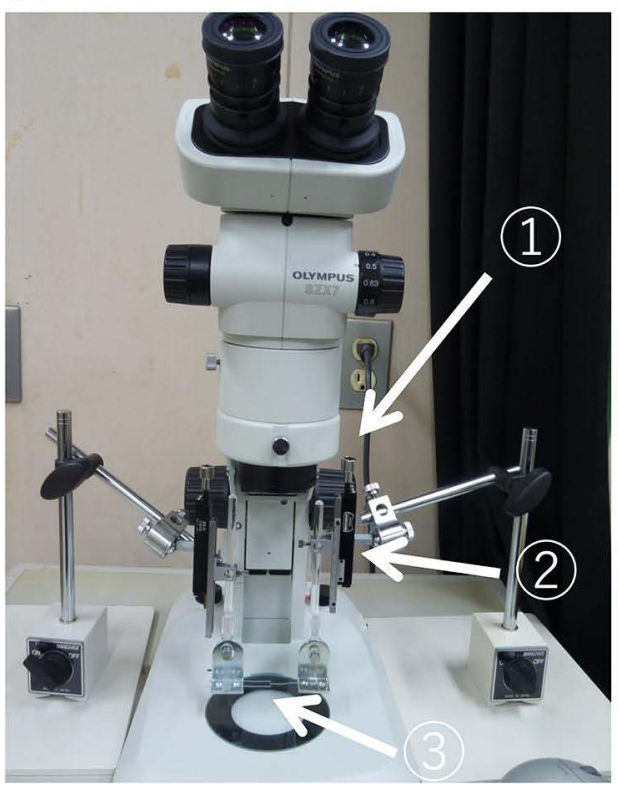

B

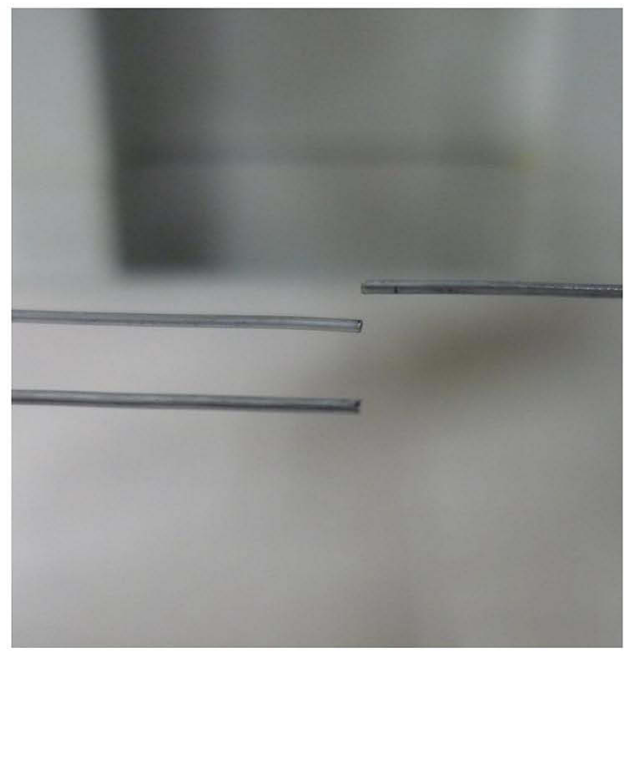

Figure I Photograph of the apparatus of M-stereotest. (A) A manipulator attached with stainless wires was set under the objective lens of a stereomicroscope. I: knob, 2: micrometer, 3: stainless wires. (B) Enlarged view of the wire section. 
(dominant and nondominant eye, contralateral eye occluded) and binocular conditions. Under the best optically corrected binocular viewing condition, both eyes were best optically corrected. Under the monocular dominant eye condition, the dominant eye was best optically corrected, whereas the nondominant eye was occluded. Under the monocular nondominant eye condition, the nondominant eye was best optically corrected, whereas the dominant eye was occluded. Under the binocular dominant eye $-3.0 \mathrm{D}$ condition, the nondominant eye was best optically corrected and a $-3.0 \mathrm{D}$ lens was added to the best optically corrected lens for the dominant eye. Under the binocular dominant eye $+3.0 \mathrm{D}$ condition, the nondominant eye was best optically corrected and a +3.0 $\mathrm{D}$ lens was added to the best optically corrected lens for the dominant eye. Under the binocular nondominant eye -3.0 $\mathrm{D}$ condition, the dominant eye was best optically corrected and $\mathrm{a}-3.0 \mathrm{D}$ lens was added to the best optically corrected lens for the nondominant eye. Finally, under the binocular nondominant eye $+3.0 \mathrm{D}$ condition, the dominant eye was best optically corrected, and a +3.0 D lens was added to the best optically corrected lens for the nondominant eye. More details are given in Table 1.

The deviation (absolute value) was measured five times for each condition, and the three values, excluding the minimum and maximum values, were averaged.

The accommodation convergence/accommodation ratio (AC/A ratio), fusional amplitude, amplitude of

Table I The Details of the Measurement Conditions

\begin{tabular}{|c|c|c|c|}
\hline & Conditions & $\begin{array}{l}\text { Dominant } \\
\text { Eye }\end{array}$ & $\begin{array}{l}\text { Nondominant } \\
\text { Eye }\end{array}$ \\
\hline I & $\begin{array}{l}\text { Best optical corrected } \\
\text { binocular condition }\end{array}$ & $\begin{array}{l}\text { Best optical } \\
\text { correction }\end{array}$ & $\begin{array}{l}\text { Best optical } \\
\text { correction }\end{array}$ \\
\hline 2 & $\begin{array}{l}\text { Monocular dominant eye } \\
\text { condition }\end{array}$ & $\begin{array}{l}\text { Best optical } \\
\text { correction }\end{array}$ & Occlusion \\
\hline 3 & $\begin{array}{l}\text { Monocular nondominant } \\
\text { eye condition }\end{array}$ & Occlusion & $\begin{array}{l}\text { Best optical } \\
\text { correction }\end{array}$ \\
\hline 4 & $\begin{array}{l}\text { Binocular dominant eye } \\
-3.0 \mathrm{D} \text { condition }\end{array}$ & $-3.0 \mathrm{D}$ & $\begin{array}{l}\text { Best optical } \\
\text { correction }\end{array}$ \\
\hline 5 & $\begin{array}{l}\text { Binocular dominant eye } \\
+3.0 \mathrm{D} \text { condition }\end{array}$ & $+3.0 \mathrm{D}$ & $\begin{array}{l}\text { Best optical } \\
\text { correction }\end{array}$ \\
\hline 6 & $\begin{array}{l}\text { Binocular nondominant eye } \\
-3.0 \mathrm{D} \text { condition }\end{array}$ & $\begin{array}{l}\text { Best optical } \\
\text { correction }\end{array}$ & $-3.0 \mathrm{D}$ \\
\hline 7 & $\begin{array}{l}\text { Binocular nondominant eye } \\
+3.0 \mathrm{D} \text { condition }\end{array}$ & $\begin{array}{l}\text { Best optical } \\
\text { correction }\end{array}$ & $+3.0 \mathrm{D}$ \\
\hline
\end{tabular}

Abbreviation: D, diopters. accommodation, and distant depth perception were measured in all participants. The eye position was measured by alternating prism cover tests at $5 \mathrm{~m}$ and $30 \mathrm{~cm}$. The $\mathrm{AC} / \mathrm{A}$ ratio was calculated from the amount of change in the best optically corrected eye position and the eye position with $-3.0 \mathrm{D}$ added, as measured by a major amblyoscope (Synoptophore: Clement Clarke, London, UK). Fusional amplitude indicators that use the major amblyoscope measure the limit angle of convergence and divergence capable binocular single vision. The amplitude of accommodation was measured using an accommodometer (Kowa NP: Kowa, Nagoya, Japan), and the distant depth perception was measured using the distance three-rods test (CP-250: Tomei, Nagoya, Japan). The three-rods test is performed using an instrument containing three black rods. The two peripheral rods are fixed, but the central rod can move from the back to the front. Participants are seated $2.5 \mathrm{~m}$ from the rods and press a button when they determine that the three rods are separated from one another by equal distances. The error distance of the center rod stopping against the two fixed rods was recorded with a $0.1-\mathrm{cm}$ unit. Best optically corrected lenses were used in all measurements. The dominant eyes were determined by the Hole-in-Card test. To confirm the reliability among examiners and the reproducibility of data, the M-stereotest with the binocular best optically corrected viewing condition was repeated twice for 15 subjects on different days.

Sigma Plot 14.0 (Systat Software Inc., San Jose, California, USA) was used for statistical analyses. To compare differences, the deviations among the binocular best optically corrected viewing condition, binocular anisometropic viewing condition, and monocular viewing condition, Friedman repeated measures of variance on ranks were used. For a pairwise multiple comparison, Tukey's test was used. Regression analysis was used to examine the relationship between the deviation by the $\mathrm{M}$-stereotest and the eye position, $\mathrm{AC} / \mathrm{A}$ ratio, fusional amplitude, amplitude of accommodation, or deviation by the distance three-rods test. A p value of $<0.05$ was considered statistically significant. The Bland-Altman analysis was used to examine intertester reliability in the M-stereotest. In addition, an interclass correlation coefficient was used to examine data reproducibility.

\section{Results}

The mean age of the subjects was $22.5 \pm 2.3$ (mean \pm standard deviation) years, and the mean refraction was $-3.96 \pm 2.50 \mathrm{D}$ and $-3.92 \pm 2.57 \mathrm{D}$ for the dominant and 
Table 2 Profile of the Subjects

\begin{tabular}{|c|c|c|c|c|}
\hline & Minimum & Maximum & Average & SD \\
\hline Age (years) & 19 & 29 & 22.5 & 2.3 \\
\hline \multicolumn{5}{|c|}{ Refraction [spherical equivalent, diopters (D)] } \\
\hline - Dominant eye & -7.50 & +0.75 & -3.96 & 2.50 \\
\hline - Nondominant eye & -8.75 & +0.50 & -3.92 & 2.57 \\
\hline \multicolumn{5}{|l|}{ Eye position (prism diopters) } \\
\hline - $30 \mathrm{~cm}$ & -20 & 0 & -6.47 & 6.67 \\
\hline - $5 \mathrm{~m}$ & -10 & 0 & -1.86 & 2.78 \\
\hline AC/A ratio (prism/diopter) & 0 & 6.33 & 2.74 & 1.7 \\
\hline Fusional amplitude (degrees) & 7.5 & 34 & 18.3 & 7.8 \\
\hline Amplitude of accommodation (D) & 6.8 & 15.4 & 10.9 & 2.0 \\
\hline The distance three-rods test $(\mathrm{cm})$ & 0.10 & 2.93 & 1.17 & 0.83 \\
\hline
\end{tabular}

Note: The distance three-rod test measured distant depth perception for inspection at a distance of $2.5 \mathrm{~m}$.

Abbreviations: AC/A ratio, accommodation convergence/accommodation ratio; SD, standard deviation.

nondominant eyes, respectively. The eye position was $-6.47 \pm 6.67$ prism diopter at $30 \mathrm{~cm}$ and $-1.86 \pm 2.78$ prism diopter at $5 \mathrm{~m}$. The $\mathrm{AC} / \mathrm{A}$ ratio was $2.74 \pm 1.7$ (prism/diopter), fusional amplitude was $18.3 \pm 7.8$ degrees, amplitude of accommodation was $10.9 \pm 2.0$ $\mathrm{D}$, and distant depth perception by the distance threerods test was $1.17 \pm 0.83 \mathrm{~cm}$. The profile of the subjects is provided in Table 2, and the results for the M-stereotest under each condition are shown in Figure 2. The deviation was significantly smaller under the binocular viewing condition than under the monocular dominant eye condition $(0.38 \pm 0.26 \mathrm{~mm}$ vs $1.89 \pm 1.15 \mathrm{~mm}, \mathrm{p}<$ 0.001 ) and the monocular nondominant eye condition $(0.38 \pm 0.26 \mathrm{~mm}$ vs $1.60 \pm 0.88 \mathrm{~mm}, \mathrm{p}<0.001)$.

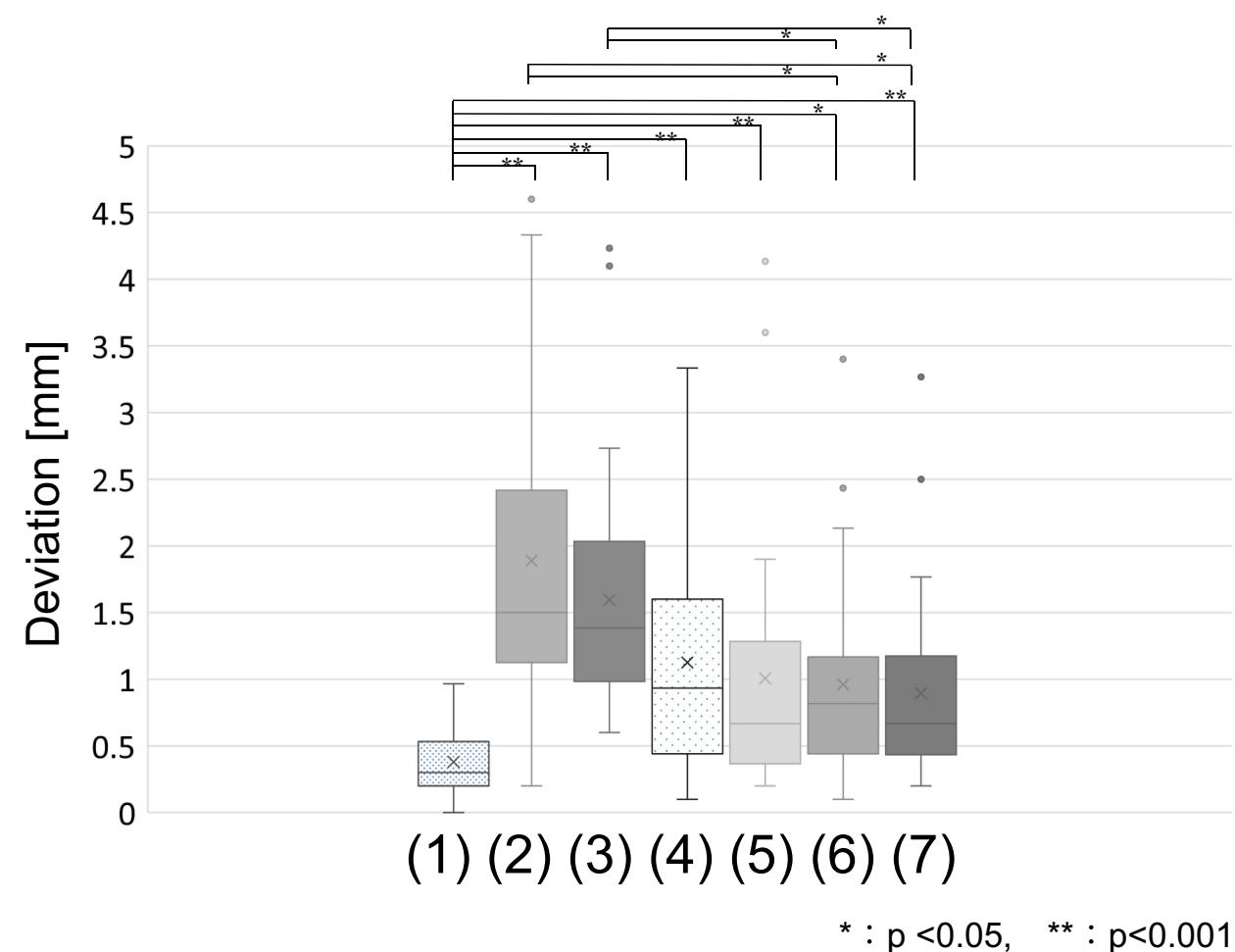

Figure 2 Deviation by M-stereotest under various conditions. (I) Best optical corrected binocular condition, (2) monocular dominant eye condition, (3) monocular nondominant eye condition, (4) binocular dominant eye $-3.0 \mathrm{D}$ condition, (5) binocular dominant eye $+3.0 \mathrm{D}$ condition, (6) binocular nondominant eye $-3.0 \mathrm{D}$ condition, (7) binocular nondominant eye $+3.0 \mathrm{D}$ condition. 
Therefore, the accuracy of depth perception under the microscope is higher under the binocular than under the monocular condition.

There was no significant difference in the amount of deviation between monocular dominant eye and monocular nondominant eye conditions. The deviation was significantly smaller in the binocular best optically corrected condition than with the binocular dominant eye -3.0 $\mathrm{D}$ condition $(1.13 \pm 0.86 \mathrm{~mm}, \mathrm{p}<0.001)$, the binocular dominant eye $+3.0 \mathrm{D}$ condition $(1.01 \pm 0.92 \mathrm{~mm}, \mathrm{p}<$ $0.001)$, the binocular nondominant eye $-3.0 \mathrm{D}$ condition $(1.07 \pm 1.00 \mathrm{~mm}, \mathrm{p}=0.003)$, or the binocular nondominant eye $+3.0 \mathrm{D}$ condition $(0.85 \pm 0.67 \mathrm{~mm}, \mathrm{p}<0.001)$. There was no significant difference in defocusing the dominant eye and the nondominant eye. The deviation of the M-stereotest under the best optically corrected binocular condition and the results of various tests were compared. There was no correlation between the deviation of M-stereotest and eye position, AC/A ratio, fusional amplitude, or amplitude of accommodation; however, a significant correlation was observed between the deviation of the M-stereotest and the distance three-rods test (Figure 3 ). The reliability among the examiners and data reproducibility in the $\mathrm{M}$-stereotest were confirmed by the Band-Altman analysis (Figure 4).

\section{Discussion}

Our results showed that in subjects with normal stereopsis, binocular vision and proper refractive correction are necessary for good depth perception under a microscope (Figure 2). Depth perception using disparity is reportedly useful in performing precise work within reach $;{ }^{9}$ therefore, the performance of surgery under microscope might be better in subjects with stereopsis than in those without stereopsis. ${ }^{10,11}$

Recently, in a study that performed simulated surgery under a microscope, better results were obtained with a binocular condition than with a monocular condition. ${ }^{12}$ Other reports showed that subjects with normal binocular vision perform better than those without binocular vision. ${ }^{13,14}$ Our results are consistent with those of previous studies. However, in reports using simulators, cataract surgery was performed by moving the hand while simultaneously looking through the microscope, thereby requiring both depth perception and motor skill. Sensory and motor fusion is of benefit when performing motor skills. ${ }^{15}$ In this manner, various factors are involved in the performance evaluation of cataract surgery. By contrast, our study was focused principally on depth perception.

In this study, we also evaluated subjects with anisometropia using $+3.0 \mathrm{D}$ or $-3.0 \mathrm{D}$ lenses added to one eye, assuming monovision or uncorrected ametropia. The results
A

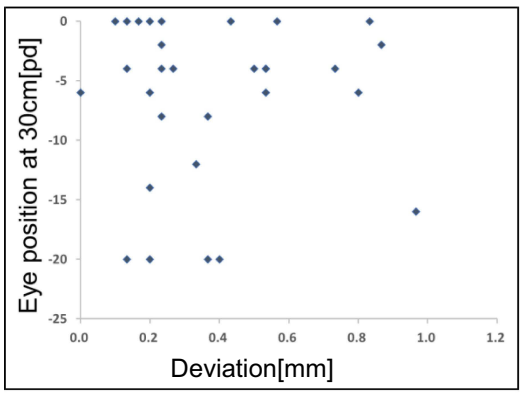

D

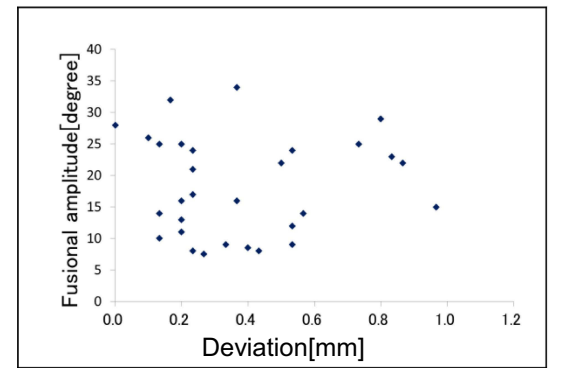

B

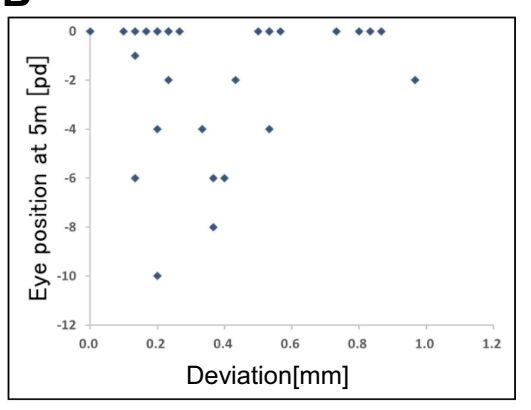

E

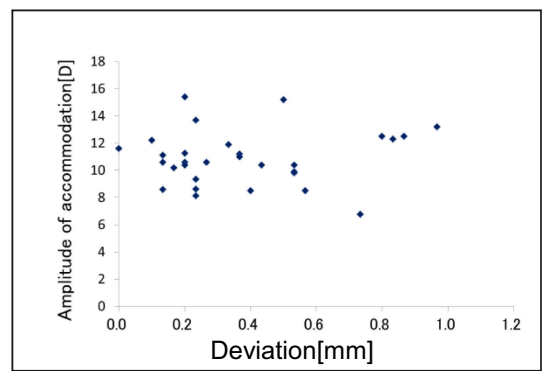

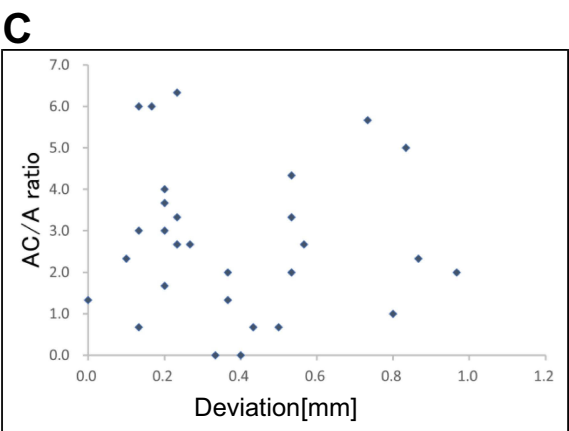

$\mathbf{F}$

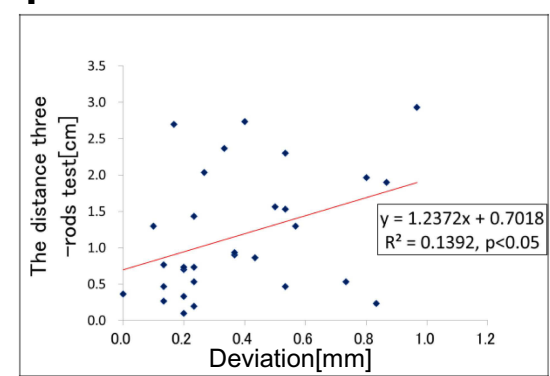

Figure 3 Relationship between the deviation of M-stereotest and eye position at $30 \mathrm{~cm}(\mathbf{A})$ and $5 \mathrm{~m}(\mathbf{B})$, AC/A ratio (C), the fusional amplitude (D), the amplitude of accommodation $(\mathbf{E})$, and the distance three-rods test $(\mathbf{F})$. Deviation indicates the deviation of M-stereotest under the best optically corrected binocular conditions. There was no correlation between the deviation of M-stereotest and either eye position, AC/A ratio, fusional amplitude, or amplitude of accommodation (A-E); however, significant correlation was observed between the deviation of M-stereotest and the distance three-rods test. (F). 


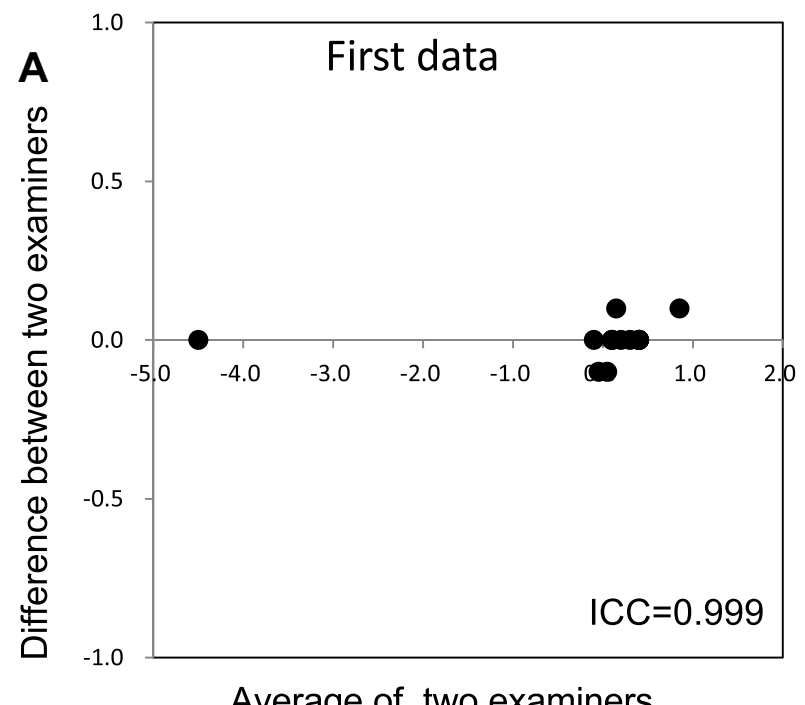

Average of two examiners

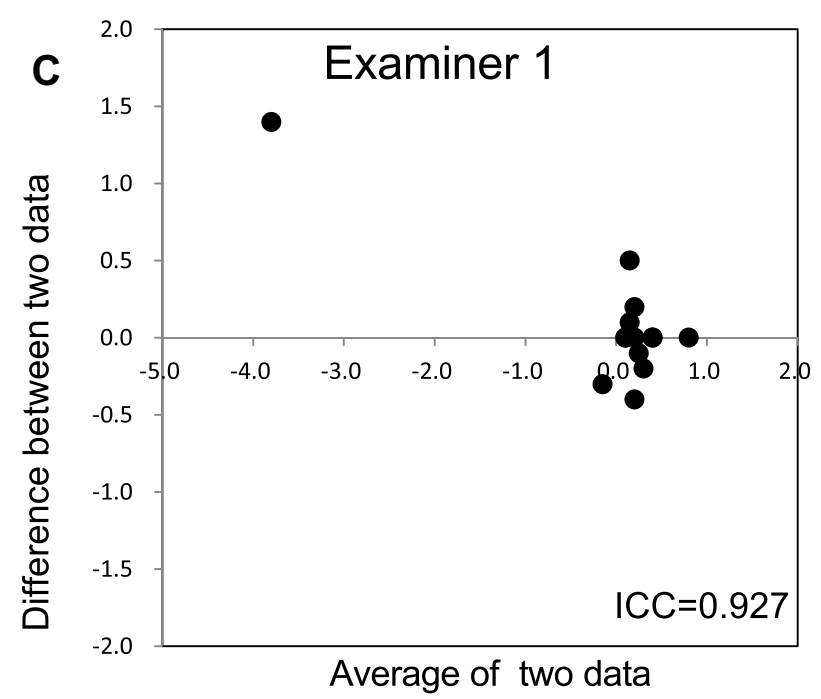

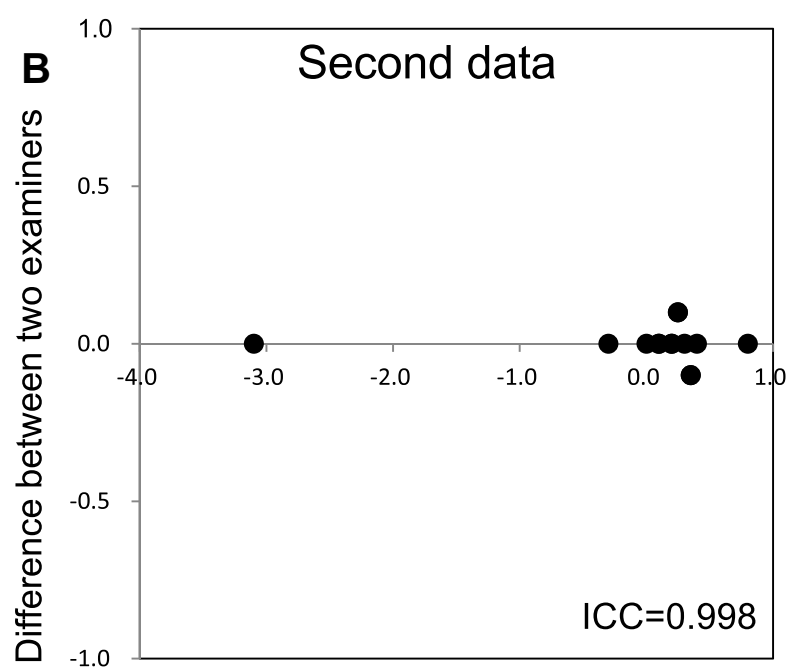

Average of two examiners

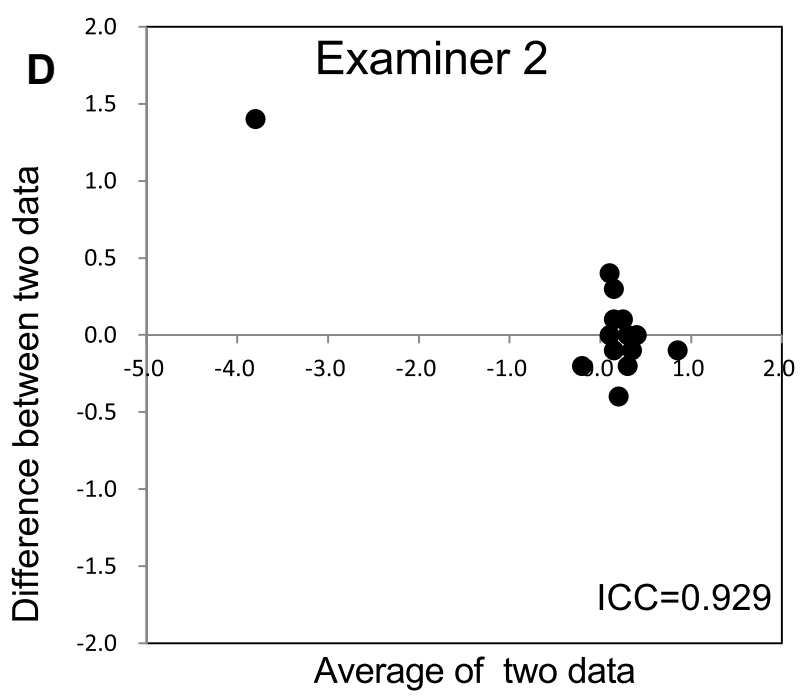

Figure 4 Bland-Altman analysis. (A) Reliability between examiners in the first data. (B) Reliability between examiners in the second data. (C) Reproducibility of the data measured by examiner I. (D) Reproducibility of the data measured by examiner 2 . For any 15 subjects, the M-stereotest with binocular best optically corrected correction was measured by the same examiner and then a different examiner. Each intraclass correlation coefficients (ICC) was high. Therefore, the reliability between the examiners and the reproducibility of the data in the M-stereotest were confirmed.

showed that even with the binocular condition, the deviation was larger in subjects with anisometropia than those with the best optically corrected vision. Cost et al reported that when +1.0 to $+5.0 \mathrm{D}$ was added to the best correction and stereoacuity were measured using the Frisby Stereo test, the addition of higher D corresponded to a lower stereoacuity. ${ }^{16}$ Other reports showed that stereopsis decreases as the degree of defocus increases. ${ }^{17,18}$ Therefore, our findings might be explained by the reduction of stereopsis because of the defocusing of one eye. Singh et al reported that anisometropia reduces not only the results of the Randot and TNO tests but also surgical skills using simulators. ${ }^{19}$ Castro et al reported that wearing contact lenses for small-diameter corneal inlays and monovision simulations reduced the results of randomdot stereoscopic tests. ${ }^{20}$ In other reports, monovision has been shown to degrade stereoscopic vision. ${ }^{21,22}$ Therefore, it is desirable to correct monovision and anisometropia during microscopic surgery, including eye surgery.

There was no correlation between the fusional amplitude and the deviation of M-stereotest under best optically corrected binocular condition. The absence of correlation between the deviation of $\mathrm{M}$-stereotest test and eye position, $\mathrm{AC} / \mathrm{A}$ ratio, and amplitude of accommodation could be a result of the normal range of the visual function of the study subjects (Table 2). 
Previous studies have reported a discrepancy between static stereopsis and dynamic stereopsis. ${ }^{23}$ The present study results showed a significant correlation between the M-stereotest and the distance three-rods test. The M-stereotest is a dynamic stereo test; hence, the deviation might be correlated with the distance three-rods test, which is also a dynamic stereo test.

The M-stereotest measures depth perception using disparity and monocular cues, such as accommodation, under binocular separating condition; hence, surgical performance could be improved by gaining experience using monocular cues, ${ }^{2}$ which is similar to our findings.

In a future study, we will investigate whether young ophthalmologists, who are beginners in using a microscope, can improve their depth perception by training with a microscope.

\section{Conclusion}

In conclusion, binocular vision and a correct refraction are both necessary to have good depth perception under a microscope. Individuals who perform well in the distance three-rods test also have good results in the stereotest with a microscope.

\section{Acknowledgments}

The authors thank N. Sonoda and M. Takahara for assistance with ophthalmic examination. The authors would also like to thank Enago for the English language review.

\section{Disclosure}

The authors report no conflicts of interest in this work.

\section{References}

1. Du LT, Wessels IF, Underdahl JP, Auran JD. Stereoacuity and depth perception decrease with increased instrument magnification: comparing a non-magnified system with lens loupes and a surgical microscope. Binocul Vis Strabismus Q. 2001;16:61-67.

2. Shah J, Buckley D, Frisby J, Darzi A. Depth cue reliance in surgeons and medical students. Surg Endosc. 2003;17(9):1472-1474. doi:10. 1007/s00464-002-9178-y

3. Mather G, Smith DR. Depth cue integration: stereopsis and image blur. Vision Res. 2000;40(25):3501-3506. doi:10.1016/S0042-6989(00)00178-4

4. Held RT, Cooper EA, Banks MS. Blur and disparity are complementary cues to depth. Curr Biol. 2012;22(5):426-431. doi:10.1016/j.cub. 2012.01.033

5. Matsuo T, Negayama R, Sakata H, Hasebe K. Correlation between depth perception by three-rods test and stereoacuity by distance rando stereotest. Strabismus. 2014;22(3):133-137. doi:10.3109/09273972. 2014.939766
6. Kani W. Stereopsis and spatial perception in amblyopes and uncorrected ametropes. $\mathrm{Br} \quad J$ Ophthalmol. 1978;62(11):756-762. doi:10.1136/bjo.62.11.756

7. Hirai A, Asonuma S, Fujikado T, et al. Evaluation of stereopsis under microscope. Ganka Rinsho Kiyo. 2009;2:149-152.

8. Hirai A, Asonuma S, Fujikado T, et al. Evaluation of stereopsis under microscope in patients with intermittent exotropia. Ganka Rinsho Kiyo. 2010;3:161-165.

9. Sheedy JE, Bailey IL, Buri M, Bass E. Binocular vs. monocular task performance. Am J Optom Physiol Opt. 1986;63(10):839-846. doi:10.1097/00006324-198610000-00008

10. Barry GP, Simon JW, Auringer D, Dunnican W, Zobal-Ratner J. Performance of strabismic subjects using a validated surgical training module: a pilot study. $J$ AAPOS. 2009;13(4):350-353.e1-2. doi:10.1016/j.jaapos.2009.05.002

11. Read JC. Visual perception: understanding visual cues to depth. Curr Biol. 2012;22(5):R163-R165. doi:10.1016/j.cub.2012.01.048

12. Waqar S, Williams O, Park J, Modi N, Kersey T, Sleep T. Can virtual reality simulation help to determine the importance of stereopsis in intraocular surgery? $\mathrm{Br} \quad J$ Ophthalmol. 2012;96(5):742-746. doi:10.1136/bjophthalmol-2011-301150

13. Sachdeva R, Traboulsi EI. Performance of patients with deficient stereoacuity on the EYESi microsurgical simulator. $\mathrm{Am}$ J Ophthalmol. 2011;151(3):427-433. doi:10.1016/j.ajo.2010.09.011

14. Selvander M, Åsman P. Stereoacuity and intraocular surgical skill: effect of stereoacuity level on virtual reality intraocular surgical performance. J Cataract Refract Surg. 2011;37(12):2188-2193. doi:10.1016/j.jcrs.2011.05.048

15. O'Connor AR, Birch EE, Anderson S, Draper H. Relationship between binocular vision, visual acuity, and fine motor skills. Optom Vis Sci. 2010;87(12):942-947. doi:10.1097/OPX.0b0 $13 \mathrm{e} 3181 \mathrm{fd} 132 \mathrm{e}$

16. Costa MF, Moreira SM, Hamer RD, Ventura DF. Effects of age and optical blur on real depth stereoacuity. Ophthalmic Physiol Opt. 2010;30(5):660-666. doi:10.1111/j.1475-1313.2010.00750.x

17. Larson WL, Bolduc M. Effect of induced blur on visual acuity and stereoacuity. Optom Vis Sci. 1991;68(4):294-298. doi:10.1097/ 00006324-199104000-00006

18. Vale A, Scally A, Buckley JG, Elliott DB. The effects of monocular refractive blur on gait parameters when negotiating a raised surface. Ophthalmic Physiol Opt. 2008;28(2):135-142. doi:10.1111/j.14751313.2008.00543.x

19. Singh P, Bergaal SK, Sharma P, et al. Effect of induced anisometropia on stereopsis and surgical tasks in a simulated environment. Indian J Ophthalmol. 2021;69(3):568-572. doi:10.4103/ijo.IJO_1540_20

20. Castro JJ, Ortiz C, Jiménez JR, Ortiz-Peregrina S, Casares-López M. Stereopsis simulating small-aperture corneal inlay and monovision conditions. J Refract Surg. 2018;34(7):482-488. doi:10.3928/ 1081597X-20180517-01

21. Westheimer G, McKee SP. Stereogram design for testing local stereopsis. Invest Ophthalmol Vis Sci. 1980;19:802-809.

22. Kirschen DG, Hung CC, Nakano TR. Comparison of suppression, stereoacuity, and interocular differences in visual acuity in monovision and acuvue bifocal contact lenses. Optom Vis Sci. 1999;76 (12):832-837. doi:10.1097/00006324-199912000-00018

23. Rouse MW, Tittle JS, Braunstein ML. Stereoscopic depth perception by static stereo-deficient observers in dynamic displays with constant and changing disparity. Optom Vis Sci. 1989;66(6):355-362. doi:10.1097/00006324-198906000-00004 


\section{Publish your work in this journal}

Clinical Ophthalmology is an international, peer-reviewed journal covering all subspecialties within ophthalmology. Key topics include: Optometry; Visual science; Pharmacology and drug therapy in eye diseases; Basic Sciences; Primary and Secondary eye care; Patient Safety and Quality of Care Improvements. This journal is indexed on PubMed
Central and CAS, and is the official journal of The Society of Clinical Ophthalmology (SCO). The manuscript management system is completely online and includes a very quick and fair peer-review system, which is all easy to use. Visit http://www.dovepress.com testimonials.php to read real quotes from published authors. 